ORIGINAL RESEARCH

\title{
Retrospective Study on Search and Rescue Operations in Two Prealps Areas of Italy
}

\author{
Marta Ciesa, PhD; Stefano Grigolato, Associate Professor; Raffaele Cavalli, Full Professor \\ From the Department of Land, Environment, Agriculture and Forestry, University of Padova, Legnaro, Italy.
}

\begin{abstract}
Objectives.-The rising number of people involved in outdoor recreation and tourism in mountain forest and wilderness areas close to urban areas has led to an increase of rescue efforts in the last decades. The study analyzes rescue operations in 2 mountain areas of the Veneto Prealps in Italy.

Methods.-A retrospective review of search and rescue incident reports for a 20-year period was performed. The study also takes into consideration any differences between accidents in the 2 areas in relation to the morphology and mountain activities involved.

Results.- There has been an increase in accidents, and the greater participation in mountain activities does not seem to be accompanied by an improvement in knowledge of the specific risks in this kind of environment. Inexperience is reflected in many reasons for callouts and is related to the remarkable rise in the number of rescued but uninjured people; the trend of fatalities and injuries is otherwise stable. Comparison of the 2 areas reveals differences in accidents mainly attributable to diversities in mountain activities involved that led to different health consequences.

Conclusions.- Search and rescue missions in mountain areas are dangerous for rescuers and made difficult by the severe environment. The knowledge of accident characteristics is therefore very important and is necessary to reduce risks for tourists and healthcare costs. To tackle the problem of safety there is also a need for more information in the form of preventive education and publicity about the typical hazards.
\end{abstract}

Key words: mountain accidents, search and rescue, Alps, hiking, mountaineering

\section{Introduction}

Mountain recreation is increasing in popularity, with some of the most typical activities being mountaineering, rock climbing, skiing, mountain running, mountain biking, backpacking, horseback riding, and mushroom picking. ${ }^{1-5}$ Despite this trend, there is still a dearth of information explaining the increase in search and rescue $(\mathrm{SAR})^{4-11}$ and the injuries and illnesses requiring SAR assistance in mountain regions popular with tourists. ${ }^{12-14}$

In Italy, SAR assistance is provided by the National Alpine Cliff and Cave Rescue Corps (CNSAS), an operational division of the Italian Alpine Club (CAI) with emergency responsibilities such as SAR missions in mountain locations. The CNSAS responds when accidents occur in hiking, mountaineering, caving, cave diving, canyoning, and natural disasters, and also in

Corresponding author: Stefano Grigolato, Department of Land, Environment, Agriculture and Forestry, University of Padova, Viale dell’Università 16, 35020 Legnaro PD, Italy (e-mail: stefano.grigolato @ unipd.it). the case of medical emergencies in wilderness areas close to urban areas. The CNSAS organization is based on regional services and coordinated at a national level. The corporation cooperates with the National Health Emergency Service and National Civil Protection Service, providing its technical and organizational capabilities in the event of disasters.

SAR rescuers operate on a volunteer basis and regularly attend training courses on rescue operations in wilderness areas and mountain environments in both summer and winter conditions. Most SAR rescuers also regularly attend medical and first aid training.

In the case of fatalities in remote and wilderness areas on steep and rocky terrain, the CNSAS cooperates with nationwide air-rescue organizations by providing technical crews; otherwise, the CNSAS operates with SAR ground crews supported by small 4-wheel-drive vehicles. $^{15}$

The first goal of the study was to gain an understanding of the rescue missions by analyzing the CNSAS SAR reports in 2 recreational and wilderness forest areas 
of the Veneto Prealps in Italy, one with a network of steep trails in a wild and rocky environment and the other with a network of gentle trails often in dense forest or areas of shrubs. A second goal was to highlight whether there were any differences between casualties and medical diagnoses for hiking and mountaineering activities in the 2 areas.

\section{Material and Methods}

\section{STUDY AREAS}

The 2 study areas are Piccole Dolomiti-Pasubio and Altopiano dei Sette Comuni, located in the Veneto Prealps in northern Italy (Figure 1). One of the key characteristics of both areas is the road and trail network that was constructed during the First World War and still widely used today for forestry, mountain recreation, and tourism. ${ }^{16}$

However, the 2 areas have very different morphological and environmental characteristics. The Piccole Dolomiti-Pasubio area offers recreational possibilities for tourists in both summer and winter. It is a mainly rocky area with a network of steep trails in a wilderness environment that discourages hiking by the inexperienced. ${ }^{15}$
The Altopiano dei Sette Comuni is a karst plateau. This topography and a good forest road network enabled the development of more than $300 \mathrm{~km}$ of trails and approximately $430 \mathrm{~km}$ of forest roads, which both provide easy walks for the inexperienced. ${ }^{16}$ Nevertheless, the widespread trail and forest road network, the endless series of valleys, hollows, and glades, and the lack of clear reference points, especially in the northern area where abandoned pasture lands are colonized by dwarf pine, ${ }^{17}$ can create problems of orientation.

\section{DATA COLLECTION}

The data for this study were collected from the SAR reports compiled by the CNSAS, an operational division of the CAI charged with emergency responsibilities in mountain locations. The format of the reports is standardized at the national level. The report contains information identifying each component of the SAR team participating in the operation; the location, date and time of the incident; the activity of the victim(s); name, sex, and age of the victim(s); description of the incident; and the resulting fatality, injury, illness, noninjury, or unknown consequence.

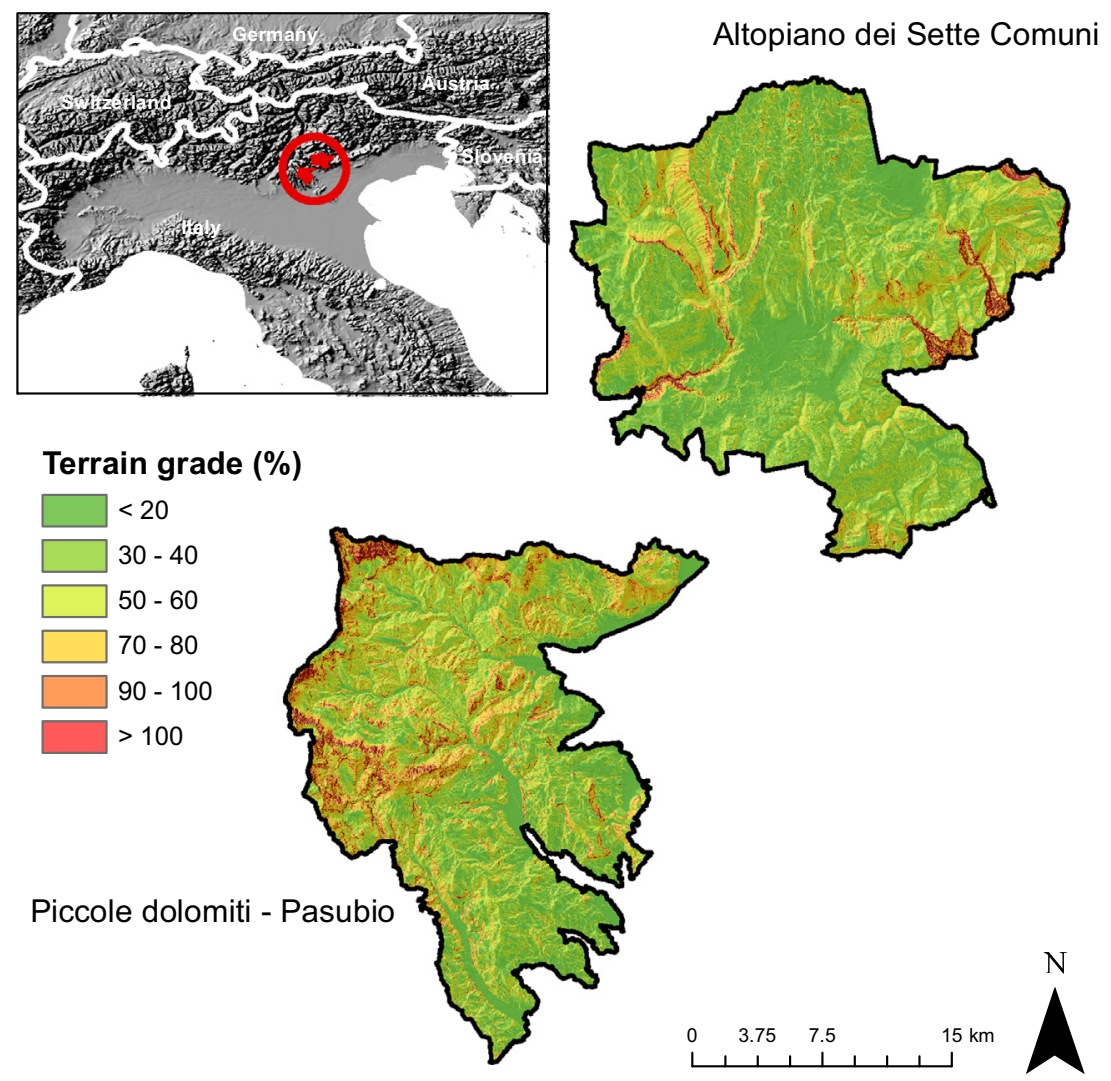

Figure 1. Maps of the 2 study areas within the Veneto Prealps in Italy. 
The data were retrieved from the SAR stations responsible for the study areas (Recoaro-Valdagno and Schio for the Piccole Dolomiti-Pasubio area and Asiago for the Altopiano dei Sette Comuni area) in hardcopy format after formal permission from the authorized delegation of the area. All the SAR reports from 1992 to 2012 were entered into a spreadsheet based on Microsoft Excel and organized for analysis. The data were then filtered only for the interventions related to recreational and tourism activities.

Data were examined to underscore the characteristics of SAR interventions according to the peculiarities of the 2 studied areas. The types of tourism and recreational activities requiring SAR intervention were very diversified, so similar categories were grouped into the same class (eg, "mountaineering" includes both rock and ice climbing; "aerial activities" comprises hang gliding, paragliding, and flying).

With the aim of better analyzing the incidents, they were categorized first into 5 main groups according to health status diagnosed for the rescued people (injured, uninjured, illness/pain, deceased, unknown). "Injured" refers to accidents in which traumas occurred; "uninjured" describes situations in which people were rescued without needing medical support; "illness and pain" refers to casualties that required medical assistance but no traumas occurred; "deceased" includes all situations in which the person was dead when the rescuers arrived; "unknown" covers all the situations in which reports do not give any information about the incident.

The detailed medical diagnosis on the SAR report is generally made after the rescue operation by the medical personal at the care center where injured people are treated. Medical diagnoses were divided into 14 groups:

- Uninjured: rescued people not injured physically

- Deceased: rescued people dead at the arrival of the SAR crew

- Fractures: rescued people with suspected broken bones

- Sprain: rescued people with a suspected traumatic injury to tendons, muscles, or ligaments

- Traumas and polytraumas: rescued people with a serious trauma to the head, spine, or abdomen. Medical diagnosis often describes a critical or lifethreatening situation

- Cardiorespiratory difficulties: rescued people with loss of consciousness, not breathing, or lacking a pulse, who are suspected of cardiac or respiratory arrest or heart attack
- Laceration or contusion: rescued people with noncritical lacerations or contusions

- Fatigue and tiredness: rescued people showing general symptoms of tiredness without other suspected complications

- Pain or illness: rescued people who were not able to continue their activity because of a sudden general pain or illness. For this condition the medical diagnosis did not report a critical or life-threatening situation

- Mental disorder: state of confusion or depression

- Dislocation: the displacement of any part of the body from its normal position, particularly a bone from its normal articulation with a joint

- Anaphylactic shock: a serious allergic reaction typically caused by insect bites or food

- Lightning: injuries caused by lightning strike

- Unknown: reports give no information about the medical diagnosis

\section{DATA ANALYSIS}

All the CNSAS SAR missions in the 2 areas from 1992 to 2012 were examined. The following information was extracted: date and location of the accident, cause of the accident, number of victims, number of SAR rescuers, and SAR vehicles supporting the mission. For each victim the following data were extracted: age, sex, city of residence, activity, and initial medical diagnosis.

The main analysis consisted of descriptive statistics. By taking into consideration the diversity of environment in the 2 study areas and assuming a relationship between the age of victims and the type of activity involved, the study also evaluated any differences in age between the 2 areas. Because of the not normally distributed population, a nonparametric test was conducted using the Mann-Whitney $U$ test with the equality of age as null hypothesis. The Mann-Whitney $U$ test also investigated any differences between injured, uninjured, deceased, and ill people. For both inferential tests, statistical significance was assumed at a probability value of less than .05 . Minitab release 14 was used for the statistical analysis (Minitab Inc, State College, PA).

\section{Results}

During the study period (from 1992 to 2012) the 3 SAR stations within the areas were involved in 835 operations with an average of 5.4 rescuers per mission, ranging from 2 to 30, for a total of 942 rescued or assisted persons. The average time for intervention was 4 hours 41 minutes with a minimum of 30 minutes and a maximum for a search activity of 73 hours. There was 


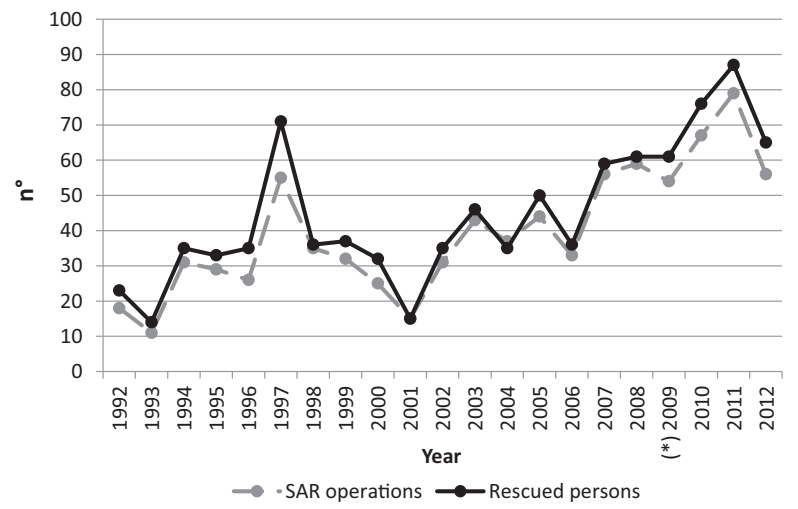

Figure 2. Trend of the total search and rescue (SAR) missions and rescued people in the 2 studied areas (*SAR information for 2009 is not available for Altopiano dei Sette Comuni).

an average of 44.8 operations per year, ranging from 11 to 79 , with a mean of 39.8 rescued persons per year, ranging from 14 to 87 (Figure 2).

It should be mentioned that SAR information concerning the Altopiano dei Sette Comuni for the year 2009 was not available. However, the missing data seem to only marginally affect the results summarized in Figure 2, which clearly show the increase of SAR operations and rescued persons between 1992 and 2012. By breaking down the data at area level, the increase of SAR operations (Figure 3) and rescued persons (Figure 4) during the study period appears to be more consistent for the Piccole Dolomiti-Pasubio than for the Altopiano dei Sette Comuni.

The average age of rescued people was 42.9 years old (SD \pm 18.920$)$; the youngest was a 6-month-old child who was rescued with his father, and the oldest was an 89-year-old woman. People's ages were split into 7 groups by 10-year intervals as shown in Figure 5.

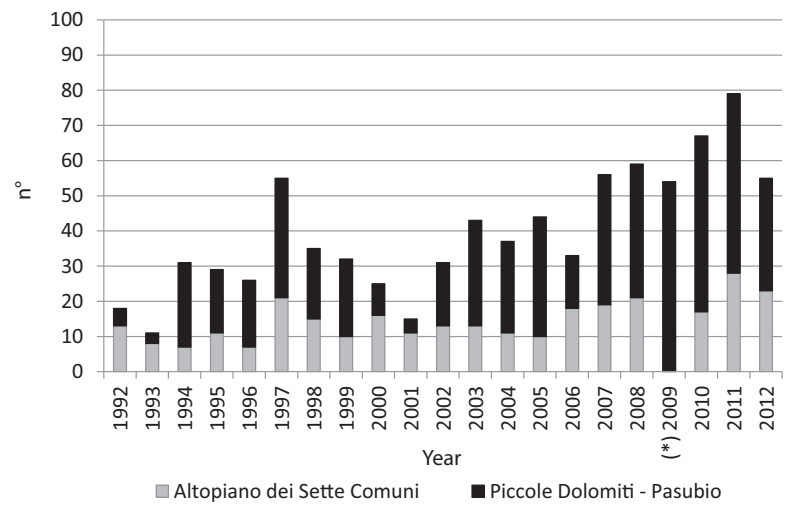

Figure 3. Annual number of search and rescue missions in each of the 2 studied areas (*search and rescue information for 2009 is not available for Altopiano dei Sette Comuni).

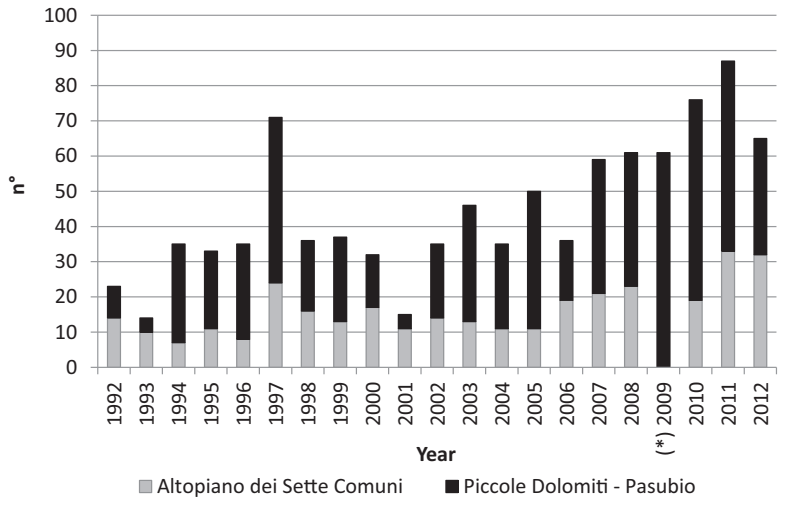

Figure 4. Annual number of rescued people in each of the 2 studied areas (*search and rescue information for 2009 is not available for Altopiano dei Sette Comuni).

The most common age groups were 25 to 35 years and 45 to 55 years. The information on age was not available for every person rescued as it was not recorded in $12 \%$ of cases; nevertheless, the mean age has increased from 37 years in the early 1990s to 45 years in 2012. The MannWhitney $U$ test for evaluation of age differences between the 2 areas reveals more elderly people were rescued in the Altopiano dei Sette Comuni than in the Piccole DolomitiPasubio area $(\mathrm{w}=148,481.0$ and $P<.01)$.

Table 1 shows the distribution of health status of the rescued people between 1992 and 2012. For all rescues, uninjured health status is dominant in the Altopiano dei Sette Comuni, whereas the dominant health status in the Piccole Dolomiti-Pasubio is injured.

During the period, approximately $66 \%$ of the total rescued people were hiking or mountaineering (Table 2). More assisted persons in both areas were hiking, whereas mountaineering was significant in Piccole DolomitiPasubio and close to zero in Altopiano dei Sette Comuni.

Analyzing the hiking and mountaineering casualties, the 3 most common causes of injuries are falling and

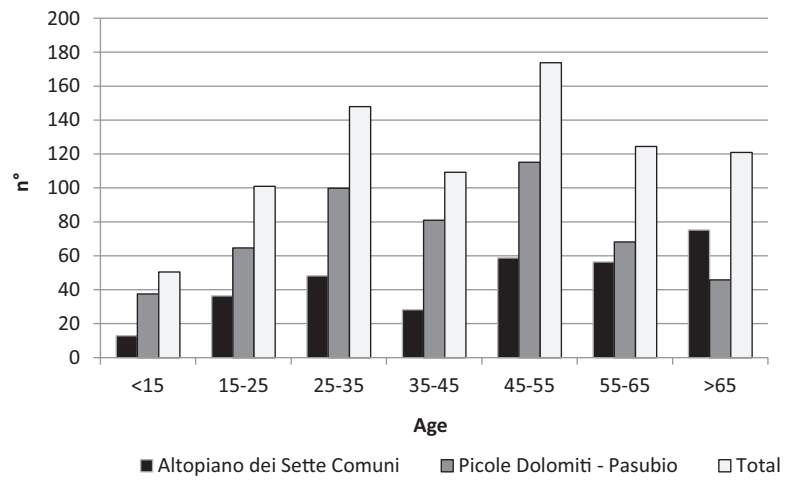

Figure 5. Age distribution of the rescued people in each of the 2 studied areas. 
Table 1. Heath status of the rescued people between 1992 and 2012

\begin{tabular}{|c|c|c|c|c|c|c|}
\hline \multirow[b]{2}{*}{ Health status } & \multicolumn{2}{|c|}{ Total } & \multicolumn{2}{|c|}{ Altopiano dei Sette Comuni } & \multicolumn{2}{|c|}{ Piccole Dolomiti-Pasubio } \\
\hline & $n$ & $\%$ & $n$ & $\%$ & $n$ & $\%$ \\
\hline Uninjured & 394 & 42 & 190 & 58 & 206 & 33 \\
\hline Injured & 369 & 39 & 78 & 24 & 290 & 47 \\
\hline Deceased & 82 & 9 & 36 & 11 & 46 & 7 \\
\hline Illness and pain & 68 & 7 & 18 & 6 & 50 & 8 \\
\hline Unknown & 29 & 3 & 5 & 2 & 23 & 4 \\
\hline Sum & 942 & 100 & 327 & 100 & 615 & 100 \\
\hline
\end{tabular}

slipping (43\%), loss of orientation (20\%), and illness (14\%). The causes of accidents differ between the 2 areas and between hiking and mountaineering (Tables 3 and 4). The most common cause of injury in the Altopiano dei Sette Comuni while hiking is related to loss of orientation (41\%), whereas in the Piccole Dolomiti-Pasubio the most important cause is falling and slipping (47\%). There were just 2 isolated cases of persons rescued while mountaineering in the Altopiano dei Sette Comuni, whereas there were 119 in the Piccole Dolomiti-Pasubio.

For hiking and mountaineering casualties, the medical diagnosis was reported for $80 \%$ of the people rescued. Tables 5 and 6 show the distribution of diagnoses for the people involved in accidents.

In the case of hiking (Table 5), $28 \%$ of the total rescued persons were uninjured. By subdividing the incidents between the 2 investigated areas, $48 \%$ were uninjured in the Altopiano dei Sette Comuni; this decreases to $19 \%$ in the Piccole Dolomiti-Pasubio. For accidents while hiking, fractures and lesions were the most common injuries (14\%), most often involving the lower extremities, whereas lesions occurred in $9 \%$ of cases. Subdividing the casualties between the 2 investigated areas, $11 \%$ of the rescued persons had fractures and lesions in the Altopiano dei Sette Comuni and $17 \%$ in the Piccole Dolomiti-Pasubio. Difference in medical diagnosis between the 2 areas is also reported for traumas and polytraumas and pain and illness, which prevail in Piccole Dolomiti-Pasubio.

Mountaineering accidents were most common in the Piccole Dolomiti-Pasubio, with 160 casualties between 1992 and 2012, whereas just 2 were recorded during the same period in the Altopiano dei Sette Comuni. In the Piccole Dolomiti-Pasubio, the medical diagnosis while mountaineering reports $14 \%$ uninjured, whereas fractures, lesions, and traumas (18\%) and polytraumas (16\%) are the most common injuries. Six percent of the people who were involved in mountaineering accidents were killed.

\section{Discussion}

During the investigated period, the CNSAS stations of Piccole Dolomiti-Pasubio and Altopiano dei Sette

Table 2. Activities of rescued people between 1992 and 2012

\begin{tabular}{|c|c|c|c|c|c|c|}
\hline \multirow[b]{2}{*}{ Activity } & \multicolumn{2}{|c|}{ Total } & \multicolumn{2}{|c|}{ Altopiano dei Sette Comuni } & \multicolumn{2}{|c|}{ Piccole Dolomiti-Pasubio } \\
\hline & $n$ & $\%$ & $n$ & $\%$ & $n$ & $\%$ \\
\hline Hiking & 453 & 48 & 186 & 57 & 267 & 43 \\
\hline Mountaineering & 162 & 17 & 2 & 1 & 160 & 26 \\
\hline Nonwood product gathering & 33 & 4 & 25 & 8 & 8 & 1 \\
\hline Car/motorbike & 30 & 3 & 16 & 5 & 14 & 2 \\
\hline Aerial activity & 27 & 3 & 7 & 2 & 20 & 3 \\
\hline Alpine skiing & 20 & 2 & 7 & 2 & 13 & 2 \\
\hline Mountain biking & 20 & 2 & 6 & 2 & 14 & 2 \\
\hline Outdoor job & 19 & 2 & 3 & 1 & 16 & 3 \\
\hline Tourism & 18 & 2 & 9 & 3 & 9 & 1 \\
\hline Hunting & 6 & 1 & 2 & 1 & 4 & 1 \\
\hline Other activity & 109 & 12 & 34 & 10 & 75 & 12 \\
\hline Unspecified & 45 & 5 & 27 & 8 & 18 & 3 \\
\hline Sum & 942 & 100 & 324 & 100 & 618 & 100 \\
\hline
\end{tabular}


Table 3. Causes of accidents for the people rescued while hiking

\begin{tabular}{|c|c|c|c|c|c|c|}
\hline \multirow[b]{2}{*}{ Causes } & \multicolumn{2}{|c|}{ Total } & \multicolumn{2}{|c|}{ Altopiano dei Sette Comuni } & \multicolumn{2}{|c|}{ Piccole Dolomiti-Pasubio } \\
\hline & $n$ & $\%$ & $n$ & $\%$ & $n$ & $\%$ \\
\hline Avalanches & 1 & 0 & 0 & 0 & 1 & 0 \\
\hline Bad weather & 8 & 2 & 4 & 2 & 4 & 1 \\
\hline Car accident & 2 & 0 & 0 & 0 & 2 & 1 \\
\hline Caving-in of handholds & 1 & 0 & 1 & 1 & 0 & 0 \\
\hline Collapse & 1 & 0 & 0 & 0 & 1 & 0 \\
\hline Falling and slipping & 155 & 34 & 50 & 27 & 105 & 39 \\
\hline Fatigue & 5 & 1 & 3 & 2 & 2 & 1 \\
\hline Illness & 64 & 14 & 23 & 12 & 41 & 15 \\
\hline Inability & 17 & 4 & 2 & 1 & 15 & 6 \\
\hline Insects/animals & 2 & 0 & 1 & 1 & 1 & 0 \\
\hline Delay & 4 & 1 & 0 & 0 & 4 & 1 \\
\hline Loss of orientation & 92 & 20 & 62 & 33 & 30 & 11 \\
\hline Rock falling & 6 & 1 & 0 & 0 & 6 & 2 \\
\hline Suicide & 1 & 0 & 0 & 0 & 1 & 0 \\
\hline Other causes & 12 & 3 & 5 & 3 & 7 & 3 \\
\hline Unknown & 82 & 18 & 35 & 19 & 47 & 18 \\
\hline Sum & 453 & 100 & 186 & 100 & 267 & 100 \\
\hline
\end{tabular}

Comuni were involved in 929 missions to rescue 969 people, $942(97.2 \%)$ of whom were retrieved during mountain activities. The study reveals a significant increase in SAR missions between 1992 and 2012. This trend is also underscored in other research ${ }^{4-8}$ that effectively attests to the rising number of accidents in rural and wild areas in recent years. The age distribution and growing number of older people could be considered indicators of a greater attraction to outdoor activities.
An overview of the activities in which rescued people were involved (Table 2) shows that hiking $(48 \%)$ and mountaineering $(17 \%)$ are the most common situations in which casualties occurred; however, there are clear differences between the 2 areas. In fact, mountaineering casualties are more frequent $(26 \%)$ in the rocky area of Piccole DolomitiPasubio, whereas casualties related to hiking (57\%) and other recreational activities such as gathering nonwood

Table 4. Causes of accidents for the people rescued while mountaineering

\begin{tabular}{|c|c|c|c|c|c|c|}
\hline \multirow[b]{2}{*}{ Causes } & \multicolumn{2}{|c|}{ Total } & \multicolumn{2}{|c|}{ Altopiano dei Sette Comuni } & \multicolumn{2}{|c|}{ Piccole Dolomiti-Pasubio } \\
\hline & $n$ & $\%$ & $n$ & $\%$ & $n$ & $\%$ \\
\hline Avalanches & 2 & 1 & 0 & 0 & 2 & 1 \\
\hline Bad weather & 4 & 2 & 0 & 0 & 4 & 3 \\
\hline Car accident & 0 & 0 & 0 & 0 & 0 & 0 \\
\hline Caving-in of handholds & 13 & 8 & 0 & 0 & 13 & 8 \\
\hline Collapse & 0 & 0 & 0 & 0 & 0 & 0 \\
\hline Falling and slipping & 59 & 36 & 0 & 0 & 59 & 37 \\
\hline Fatigue & 1 & 1 & 0 & 0 & 1 & 1 \\
\hline Illness & 5 & 3 & 0 & 0 & 5 & 3 \\
\hline Inability & 14 & 9 & 1 & 1 & 13 & 8 \\
\hline Insects/animals & 0 & 0 & 0 & 0 & 0 & 0 \\
\hline Delay & 0 & 0 & 0 & 0 & 0 & 0 \\
\hline Loss of orientation & 7 & 4 & 1 & 1 & 6 & 4 \\
\hline Rock falls & 15 & 9 & 0 & 0 & 15 & 9 \\
\hline Suicide & 0 & 0 & 0 & 0 & 0 & 0 \\
\hline Unknown & 42 & 26 & 0 & 0 & 42 & 26 \\
\hline Sum & 162 & 100 & 2 & 100 & 160 & 100 \\
\hline
\end{tabular}


Table 5. Medical diagnosis of the casualties while hiking

\begin{tabular}{|c|c|c|c|c|c|c|}
\hline \multirow[b]{2}{*}{ Medical diagnosis } & \multicolumn{2}{|c|}{ Total } & \multicolumn{2}{|c|}{ Altopiano dei Sette Comuni } & \multicolumn{2}{|c|}{ Piccole Dolomiti-Pasubio } \\
\hline & $n$ & $\%$ & $n$ & $\%$ & $n$ & $\%$ \\
\hline Uninjured & 129 & 28 & 77 & 41 & 52 & 19 \\
\hline Deceased & 23 & 5 & 12 & 6 & 11 & 4 \\
\hline Fractures & 65 & 14 & 20 & 11 & 45 & 17 \\
\hline Sprains & 17 & 4 & 7 & 4 & 10 & 4 \\
\hline Traumas and polytraumas & 36 & 8 & 5 & 3 & 31 & 12 \\
\hline Cardiorespiratory difficulties & 13 & 3 & 5 & 3 & 8 & 3 \\
\hline Lacerations or contusions & 24 & 5 & 9 & 5 & 15 & 6 \\
\hline Fatigue and tiredness & 11 & 2 & 4 & 2 & 7 & 3 \\
\hline Pain or illness & 29 & 6 & 7 & 4 & 22 & 8 \\
\hline Mental disorder & 6 & 1 & 3 & 2 & 3 & 1 \\
\hline Dislocation & 8 & 2 & 2 & 1 & 6 & 2 \\
\hline Anaphylactic shock & 1 & 0 & 1 & 1 & 0 & 0 \\
\hline Lightning & 1 & 0 & 0 & 0 & 1 & 0 \\
\hline Unknown & 90 & 20 & 34 & 18 & 56 & 21 \\
\hline Sum & 453 & 100 & 186 & 100 & 267 & 100 \\
\hline
\end{tabular}

products $(8 \%)$ are more recurrent in the gentler area of the Altopiano dei Sette Comuni.

Regarding the age of the rescued victims, the difference between the 2 areas is significant. More elderly people are rescued in the Altopiano dei Sette Comuni than in the Piccole Dolomiti-Pasubio. In the former, the analysis of accidents reveals a higher number of people involved in so-called "soft" activities than in "hard" ones. ${ }^{18}$ Instead, the rockier area of Piccole DolomitiPasubio is frequented mostly by younger people undertaking more physically demanding activities that also generally lead to more serious consequences when accidents happen. In the Piccole Dolomiti-Pasubio, where mountaineering is popular, the median age of the rescued persons (40 years) was lower than in the Altopiano dei Sette Comuni (49 years), where hiking, tourism, and recreational activities such as gathering nonwood products are predominant. In fact, the average age of victims involved in mountaineering was 37.6 years (SD \pm 11.6 ), whereas for hiking and gathering nonwood products it was 44.6 years $( \pm 32.2)$ and 62.1 years $( \pm 11.2)$, respectively.

As concerns the SAR missions, most interventions for uninjured (Table 1) were a result of people rescued

Table 6. Medical diagnosis of the casualties while mountaineering

\begin{tabular}{|c|c|c|c|c|c|c|}
\hline \multirow[b]{2}{*}{ Medical diagnosis } & \multicolumn{2}{|c|}{ Total } & \multicolumn{2}{|c|}{ Altopiano dei Sette Comuni } & \multicolumn{2}{|c|}{ Piccole Dolomiti-Pasubio } \\
\hline & $n$ & $\%$ & $n$ & $\%$ & $n$ & $\%$ \\
\hline Uninjured & 24 & 15 & 2 & 100 & 22 & 14 \\
\hline Deceased & 10 & 6 & 0 & 0 & 10 & 6 \\
\hline Fractures & 28 & 17 & 0 & 0 & 28 & 18 \\
\hline Sprains & 2 & 1 & 0 & 0 & 2 & 1 \\
\hline Traumas and polytraumas & 25 & 15 & 0 & 0 & 25 & 16 \\
\hline Cardiorespiratory difficulties & 1 & 1 & 0 & 0 & 1 & 1 \\
\hline Lacerations or contusions & 7 & 4 & 0 & 0 & 7 & 4 \\
\hline Fatigue and tiredness & 1 & 1 & 0 & 0 & 1 & 1 \\
\hline Pain or illness & 2 & 1 & 0 & 0 & 2 & 1 \\
\hline Mental disorder & 0 & 0 & 0 & 0 & 0 & 0 \\
\hline Dislocation & 1 & 1 & 0 & 0 & 1 & 1 \\
\hline Anaphylactic shock & 61 & 38 & 0 & 0 & 61 & 38 \\
\hline Lightning & 0 & 0 & 0 & 0 & 0 & 0 \\
\hline Unknown & 0 & 0 & 0 & 0 & 0 & 0 \\
\hline Sum & 24 & 15 & 2 & 100 & 22 & 14 \\
\hline
\end{tabular}


without any health problems who called for aid mainly because of loss of orientation and inability; in these cases the generic medical diagnosis is recorded as uninjured. The uninjured category also involved other medical diagnoses such as people affected by psychiatric problems who were generally lost and are recorded as psychiatric causes.

The medical diagnosis is strongly correlated to the type of activities. More dangerous activities led to more serious medical diagnoses. Traumas/polytraumas or fractures were more common in the Piccole DolomitiPasubio where mountaineering casualties are more frequent than in the Altopiano dei Sette Comuni where mountaineering is marginal.

The Altopiano dei Sette Comuni shows the highest number of uninjured people (Table 1) and callouts were mainly for loss of orientation, as it is characterized by extensive wooded areas, high forest road density, and many places that are similar, and secondarily for inability. In this area, callouts seemed to be attributable more to an inadequate preparation of people rescued, which denotes a general underestimation of the risks in these places. It generally seems that people involved in more risky activities are more aware of dangers than people involved in safer ones; this is made clear by comparison of the casualty results for mountaineers and hikers. The intrinsic risks of mountaineering make it less popular than hiking and thus fewer accidents are recorded. Moreover, the high level of fitness and knowledge of the mountaineers' surroundings further reduce the chances of accidents, but when they happen, they more often involve serious injuries. Indeed, $26 \%$ were lethal and injuries occurred in more than half of the cases.

On the other hand, many hikers were rescued uninjured or with less serious problems than mountaineers: $40.3 \%$ of hikers were uninjured vs $19 \%$ of mountaineers. These results are consistent with other research ${ }^{19,20}$ that attests to mountaineering and hiking becoming more popular and widespread and the high rate of hikers involved in rescue missions with an overall low severity. ${ }^{8,11,21}$

It also appears that currently SAR crews are called out more than in the past for people who are late in returning, exhausted, or in trouble because of bad weather. The analysis of the description of the callouts for uninjured persons noted in the CNSAS reports reveals an underestimation of the environment characteristics, as attested to by many cases of loss of orientation. In addition, poor evaluation of their physical capabilities leads to excessive effort in people who are not sufficiently fit and an increase in falling and slipping accidents caused by tiredness or distraction. Another evidence of carelessness in mountain areas is the high number of missions to rescue uninjured people, which has significantly increased in 20 years mainly because of loss of orientation or lack of ability, especially when hiking. Significant resources were mobilized to rescue uninjured people (5.8 rescuers per operation, with an average intervention time of 4 hours 10 minutes) for SAR but not for medical care.

The evaluation of wilderness accidents related to environmental characteristics has confirmed the importance of the environment on the type of casualties. This aspect is important as it allows the management of risks to be better evaluated; knowledge of the main risks in an area is also useful to improve public information for visiting tourists.

Local characteristics are very important in defining the main feasible outdoor activities and, therefore, the main risks or possible accidents; this can allow SAR services to focus more attention on specific places or activities and to convey clear and targeted information. Training programs for rescuers can also be targeted to the main problematic aspects of the area where they operate.

\section{Conclusions}

The analysis of SAR interventions between 1992 and 2012 in 2 different forest and mountainous areas of the Veneto Prealps in Italy provided a useful comprehensive overview of casualties related to recreation and tourism in wilderness areas. The increasing number of casualties in activities such as hiking and mountaineering in the 2 investigated areas is similar to that of other wilderness or natural areas. However, there is a significant difference between the 2 areas in terms of age and type of injuries. In the rocky area, mountaineering attracts younger people and the injuries are more severe than in the area with forests and shrubs where hiking and gathering nonwood products are the predominant activities. It also confirmed that musculoskeletal injuries to extremities often occur while hiking on trails, but most callouts are related to uninjured persons asking for help because of their lack of preparation and underestimation of the difficulties or weather conditions.

The results of this work thus represent an important step to evaluate future activities to decrease the number of casualties by promoting knowledge on spending time in mountain wilderness areas, and also in terms of "soft" activities such as hiking or gathering nonwood products, and by educating on the proper use of equipment and evaluation of the trail in relation to the weather conditions.

The results can also give useful information to identify the most efficient SAR crew formation in terms of 
medical knowledge and medical equipment, but also in terms of vehicles and transport equipment in relation to the most frequent types of medical diagnosis.

In general this analysis should provide useful aspects for understanding the main risks associated with spending time in the mountains.

\section{Acknowledgments}

We thank Giorgio Cocco, who is in charge of the Prealpi Venete CNSAS delegation, and the CNSAS stations of Asiago, Recoaro-Valdagno, and Schio for providing the data.

\section{References}

1. Heggie TW, Heggie TM. Viewing lava safely: an epidemiology of hiker injury and illness in Hawaii Volcanoes National Park. Wilderness Environ Med. 2004;15:77-81.

2. Yang YJ, Wang TL. Mountain rescue and search in Taiwan. Ann Disaster Med. 2004;3(suppl 1):S30-S34.

3. Yarwood R. One moor night: emergencies, training and rural space. Area. 2012;44:22-28.

4. Lischke V, Byhahn C, Westphal K, Kessler P. Mountaineering accidents in the European Alps: have the numbers increased in recent years? Wilderness Environ Med. 2001;12:74-80.

5. Heggie TW, Heggie TM. Search and rescue trends associated with recreational travel in US national parks. J Travel Med. 2009;16:23-27.

6. Durrer B. Rescue operations in the Swiss Alps in 1990 and 1991. Wilderness Environ Med. 1993;4:363-373.

7. Mort AJ, Godden DJ. UK mountain rescue casualties: 2002-2006. Emerg Med J. 2010;27:309-312.

8. Schmidt TA, Federiuk CS, Zechnich A, Forsythe M, Christie M, Andrews C. Advanced life support in the wilderness: 5 year experience of the Reach and Treat team. Wilderness Environ Med. 1996;3:208-215.

9. Johnson L. An introduction to mountain search and rescue. Emerg Med Clin North Am. 2004;22:511-524.
10. Kaufmann M, Moser B, Lederer W. Changes in injury patterns and severity in a helicopter air-rescue system over a 6-year period. Wilderness Environ Med. 2006;17:8-14.

11. Heggie TW, Amundson ME. Dead men walking: search and rescue in US National Parks. Wilderness Environ Med. 2009;20:244-249.

12. Chamarro A, Fernández-Castro J. The perception of causes of accidents in mountain sports: a study based on the experiences of victims. Accid Anal Prev. 2009;41:197201.

13. Salmon PM, Goode N, Lenné MG, Finch CF, Cassell E. Injury causation in the great outdoors: a systems analysis of led outdoor activity injury incidents. Accid Anal Prev. 2014;63:111-120.

14. Schad R. Analysis of climbing accidents. Accid Anal Prev. 2000;32:391-396.

15. Ciesa M, Grigolato S, Cavalli R. Analysis on vehicle and walking speeds of search and rescue ground crews in mountainous areas. J Outdoor Recreat Tourism. 2014;56:48-57.

16. Cavalli R, Grigolato G, Pellegrini M. The evolution of a mountain road network from its original use during the First World War to meeting today's forestry needs: current management. J Agric Eng. 2012;43:123-129.

17. Cavalli R, Pellegrini M, Grigolato S, Bietresato M. A strategy for the management of abandoned mountain pasture land colonised by dwarf pine. Ital J Forest Mountain Environ. 2011;66:383-393.

18. Beedie P, Hudson S. Emergence of mountain-based adventure tourism. Ann Tourism Res. 2003;30:625-643.

19. Heggie TW. Search and rescue in Alaska's national parks. Travel Med Infect Dis. 2008;6:355-361.

20. Malcom M. Mountaineering fatalities in Mt Cook National Park. N Z Med J. 2001;9:78-80.

21. Hung EK, Townes DA. Search and rescue in Yosemite National Park: a 10-year review. Wilderness Environ Med. 2007;18:111-116. 